\title{
Acceptance and Readiness to Use M-Learning among Primary School Science Teachers
}

\author{
Mohd Razali Abd Samad, Zanaton Haji Iksan, Fariza Khalid \\ Faculty of Education, Universiti Kebangsaan Malaysia, Bangi Selangor, Malaysia \\ Email:p92833@siswa.ukm.edu.my
}

How to cite this paper: Samad, M. R. A., Iksan, Z. H., \& Khalid, F. (2019). Acceptance and Readiness to Use M-Learning among Primary School Science Teachers. Creative Education, 10, 3003-3011. https://doi.org/10.4236/ce.2019.1012224

Received: October 21, 2019

Accepted: November 26, 2019

Published: November 29, 2019

Copyright (c) 2019 by author(s) and Scientific Research Publishing Inc. This work is licensed under the Creative Commons Attribution International License (CC BY 4.0).

http://creativecommons.org/licenses/by/4.0/ (c) (i) Open Access

\begin{abstract}
Consolidating and implementing educational strategies using $21^{\text {st }}$ century methods in the country's present education system have changed the landscape of education in Malaysia. The educator's role becomes easier when the conventional style of teaching and learning shifts to learning and facilitating. The Ministry of Education, in the implementation of the Malaysia Education Blueprint 2013-2025, has targeted for all children in Malaysia to be equipped with six main attributes to meet the skill requirements by 2025 . These six main attributes are: 1) knowledge; 2) thinking skills; 3) leadership skills; 4) bi-linguistic proficiency; 5) ethics and spirituality; and 6) national identity. Among the skills needed in 21st century learning are creative thinking skills, critical thinking skills, communication skills, and collaboration skills (Partnership for 21st century skills/P21). Among the initiatives taken is the application of Information and Communications Technology (ICT) in education. This step is taken to pioneer the way towards achieving learning by using ICT innovation. The objective of this paper is to determine the level of acceptance and readiness of science teachers to use mobile learning (M-Learning) as well as the suitability of using M-Learning among primary school science teachers. A total of 125 primary school science teachers from the state of Johor were involved in this study. A questionnaire containing 10 items was used as an instrument, and the data obtained were analyzed using the SPPS version 22 software. The reliability value of the instrument according to Cronbach's Alpha for all variables falls between 0.922 and 0.943 . Hence, the findings show a high level of acceptance and readiness to use M-Learning among primary school science teachers.
\end{abstract}

\section{Keywords}

$21^{\text {st }}$ Century Education, Teaching and Learning, M-Learning, Science Education, Mobile Learning 


\section{Introduction}

In education, mobile learning (M-Learning) is known as a style of teaching and learning that makes use of mobile devices such as smartphones, laptops, Chromebooks, netbooks, and tablets (Taylor \& Sharples, 2006). Norlidah (2013) stated that M-Learning is a learning method that is not bound by geographical factors, time, and place. Success in M-Learning has been observed in countries such as South Korea, Japan, the United Kingdom, and the United States.

This can be seen from the notes-sharing method carried out among students using mobile devices.

According to Ronizam, Shahrul Niza, Norzaimah, and Dina (2016), the use of Wi-Fi in education can contribute towards narrowing the digital divide among the population of developing nations. Through the use of smartphones, M-Learning can incorporate features such as sending and receiving emails, pictures, Short Messaging System (SMS), and Multimedia Messaging System (MMS), where messages can be received in the form of music, pictures, animation, and short videos (Lu, Liu, \& Wei, 2017; Jaafar, \& Lee, 2018). Therefore, M-Learning clearly has the potential to be developed in schools, especially in the school curriculum programme based on the Standard Curriculum and Assessment Documents. Teaching and learning activities such as Project Based Learning and Problem Based Learning can benefit from the use of mobile applications (Karch, 2014). Mobile devices provide opportunities for students to engage either inside or outside the classroom through the use of online and mobile technology applications (Rikala, Hiltunen, \& Vesisenaho, 2014). One example of the implementation of M-Learning is flipped classroom (Shi, Luo, \& $\mathrm{He}, 2017)$

Ahmed and Parsons (2013) viewed "Mobile-Learning" as the delivery of distance-learning content. Mobile Learning is known as a novel approach that allows learning to be experienced anytime and anywhere. In essence, learning is a process whereby a student can achieve the expected learning outcomes (Lu et al., 2017) and such learning outcomes must be measured to ensure that the proper learning process has taken place. Teachers must act as facilitators and arm themselves with teaching aids such as LCDs, reading materials, notes, and other communication tools. This can create a more exciting and useful learning experience for students in achieving the expected learning outcomes.

One of the methods of learning is through the use of mobile technology (Camilleri et al., 2017). Mobile devices such as mobile phones and tablets are among the equipment that can help to improve and enhance the learning process. The use of the current smartphone is not limited to communication; it also extends to other functions such as accessing the internet and creating and accessing documents and file data. In addition, devices such as smartphones, tablets, and iPads are becoming more innovative; the latest technology has allowed integration between computing and communication systems. This technology provides an easier way to receive emails, multimedia or text messages, lecture notes, and 
to use video in $3 \mathrm{G}$ format. Through using mobile phones, one can find information on the internet, synthesize the information and then build up the information to become a more meaningful form of knowledge (Cheong, Bruno, \& Cheong, 2012). Although the students are in Generation Y and Generation Z groups, or at least are familiar with the use of mobile technology, their level of acceptance and readiness to receive technology in the learning and facilitating environment have not been correctly identified. Teachers today face various issues, situations, and challenges in respect of education (Jou, Lin, \& Tsai, 2016). The existence of new technology means that information is processed differently and assessment in learning and facilitating must also be done differently (Roblyer, McDaniel, Webb, Herman, \& Witty, 2013) Mobile phones are tools that assist in the learning and facilitating process in educational institutions. The community in Malaysia has begun to accept the usage of mobile phones in education. Several schools have begun to use mobile phones in the classroom for purposes of learning and facilitating. Malaysia has also conducted pilot studies on the implementation of mobile phone usage, such as the study of "I-Phone Use in Virtual Learning” (Ismail, Bokhare, Azizan, \& Azman, 2013). This measure is still under-practised in the learning of science subjects in primary schools. Therefore, there is a gap to be explored by the researcher.

Teachers' education should not be focused on knowledge and pedagogy separately. Mobile learning has spurred collaboration and control over content which is no longer centred and it allows students to produce, publish, and share information. The use of mobile device technology can actively engage students in the form of group collaboration (Pritchett, Wohleb Pritchett, 2013; Rian \& Kamisah, 2018). Examples of the usage of mobile device technology are the production of blogs, weblogs, podcasts, and wikis. Therefore, applications in mobile devices have great potential to support the implementation of the science curriculum in school.

Additionally, mobile devices can improve social communication and interaction among users (Park, 2013; Norazah \& Helmi, 2018) such as the usage of Google Docs, blogs, Facebook, Twitter, and so on. Without the full acceptance and readiness of all parties, especially teachers, the implementation of M-Learning may not run smoothly. Therefore, this study is vital because acceptance and readiness are necessary factors to enable the teaching and learning process to be carried out in an engaging M-Learning environment. This study aims to identify the level of acceptance and readiness of teachers towards M-Learning, as part of the efforts taken to implement $21^{\text {st }}$ century approach to learning in primary schools.

\section{Methodology}

A quantitative descriptive study was carried out to evaluate the level of acceptance and readiness to use M-Learning among primary school science teachers in the state of Johor. The questionnaire was chosen as the method to collect data from respondents. The respondents were selected based on simple random sam- 
pling. A total of 125 primary school teachers from the state of Johor were selected to be respondents in this study. The research instrument was built by the researcher based on the questionnaire by $\mathrm{Oz}$ (2014), using a five-point Likert scale (strongly disagree, disagree, uncertain, agree, and strongly agree) and containing ten items.

To test the items in the questionnaire, a pilot study was conducted to assess the overall suitability of the instrument to the respondents and the extent to which the respondents understood each statement used. The pilot study had been conducted earlier on 31 respondents to determine the reliability of the questionnaire. The Section contained two constructs. The first construct, which contained five items, was related to the science teachers' level of acceptance of using M-Learning. The second construct, which contained five items, was related to the science teacher's level of readiness to use M-Learning. The Alpha Cronbach values for all variables were recorded between 0.922 and 0.943 . The aspect of acceptance of M-Learning showed the value of Alpha Cronbach to be 0.922 , and the aspect of readiness to use M-Learning showed the value to be 0.943 . The questionnaire was distributed to all respondents who were each given 15 minutes to answer the questions before returning the questionnaire to the researcher.

\section{Results}

\subsection{The Level of Acceptance by Science Teachers to Use M-Learning}

Table 1 shows the frequency and percentage scores for each item related to science teachers' acceptance of the use of M-Learning. The highest mean value was for the item "I use mobile devices because it has a combination of audio, multimedia and visual functions" (4.448), whilst the lowest mean value was for the item " $I$ use mobile devices during teaching because of my interest in it" (4.088).

Based on the findings shown in Table 1, most items scored a mean value of more than 4 , which indicates that teachers accept mobile learning in teaching and learning science. The overall mean value according to Table 1 is more than 4. This shows that primary school science teachers in the state of Johor accept the use of M-Learning during their teaching and learning sessions. This finding also shows that respondents put high expectations on the performance of M-Learning if it was to be implemented in formal learning.

\subsection{The Level of Readiness of Science Teachers to Use M-Learning}

Table 2 shows the frequency and percentage score for each item measuring the readiness of science teachers to use M-Learning. The item with the highest mean value was "I am ready to apply m-learning in the future" (4.072), whereas, the item with the lowest mean value was "I am ready to face the problems when I use mobile devices during teaching and learning sessions" (3.664). Overall, as 
Table 1. Percentage score for each item measuring the acceptance of M-learning.

\begin{tabular}{|c|c|c|c|c|c|c|c|}
\hline & & & & & & & Standard \\
\hline Statement & 1 & 2 & 3 & 4 & 5 & Mean & Deviation \\
\hline $\begin{array}{l}\text { I use mobile devices because it } \\
\text { facilitates my teaching }\end{array}$ & $\begin{array}{c}2 \\
(1.6 \%)\end{array}$ & $\begin{array}{c}0 \\
(0.0 \%)\end{array}$ & $\begin{array}{c}4 \\
(3.2 \%)\end{array}$ & $\begin{array}{c}76 \\
(60.8 \%)\end{array}$ & $\begin{array}{c}43 \\
(34.4 \%)\end{array}$ & 4.264 & 0.673 \\
\hline $\begin{array}{l}\text { I use mobile devices during } \\
\text { teaching because of my interest } \\
\text { in it }\end{array}$ & $\begin{array}{c}1 \\
(0.8 \%)\end{array}$ & $\begin{array}{c}6 \\
(4.8 \%)\end{array}$ & $\begin{array}{c}7 \\
(5.6 \%)\end{array}$ & $\begin{array}{c}78 \\
(62.4 \%)\end{array}$ & $\begin{array}{c}33 \\
(26.4 \%)\end{array}$ & 4.088 & 0.762 \\
\hline $\begin{array}{l}\text { I use mobile devices because it } \\
\text { has a combination of }\end{array}$ & $\begin{array}{c}2 \\
(1.6 \%)\end{array}$ & $\begin{array}{c}0 \\
(0.0 \%)\end{array}$ & $\begin{array}{c}1 \\
(0.8 \%)\end{array}$ & $\begin{array}{c}59 \\
(47.2 \%)\end{array}$ & $\begin{array}{c}63 \\
(50.4 \%)\end{array}$ & 4.448 & 0.677 \\
\hline
\end{tabular}

Table 2. Percentage score for each item measuring the readiness to use M-Learning.

\begin{tabular}{|c|c|c|c|c|c|c|c|}
\hline & & & & & & & Standard \\
\hline Statement & 1 & 2 & 3 & 4 & 5 & Mean & Deviation \\
\hline $\begin{array}{l}\text { I am ready to use mobile } \\
\text { devices during learning and } \\
\text { facilitating sessions }\end{array}$ & $\begin{array}{c}1 \\
(0.8 \%)\end{array}$ & $\begin{array}{c}4 \\
(3.2 \%)\end{array}$ & $\begin{array}{c}9 \\
(7.2 \%)\end{array}$ & $\begin{array}{c}82 \\
(65.6 \%)\end{array}$ & $\begin{array}{c}29 \\
(23.2 \%)\end{array}$ & 4.070 & 0.709 \\
\hline $\begin{array}{l}\text { I am ready to face the } \\
\text { problems when I use mobile } \\
\text { devices during learning and } \\
\text { facilitating sessions }\end{array}$ & $\begin{array}{c}2 \\
(1.6 \%)\end{array}$ & $\begin{array}{c}12 \\
(9.6 \%)\end{array}$ & $\begin{array}{c}23 \\
(18.4 \%)\end{array}$ & $\begin{array}{c}77 \\
(61.6 \%)\end{array}$ & $\begin{array}{c}11 \\
(8.8 \%)\end{array}$ & 3.664 & 0.832 \\
\hline $\begin{array}{l}\text { I know how to use every } \\
\text { application in the mobile } \\
\text { device }\end{array}$ & $\begin{array}{c}1 \\
(0.8 \%)\end{array}$ & $\begin{array}{c}10 \\
(8 \%)\end{array}$ & $\begin{array}{c}26 \\
(20.8 \%)\end{array}$ & $\begin{array}{c}74 \\
(59.2 \%)\end{array}$ & $\begin{array}{c}14 \\
(11.2 \%)\end{array}$ & 3.720 & 0.799 \\
\hline $\begin{array}{l}\text { I am ready to involve } \\
\text { myself in M-Learning }\end{array}$ & $\begin{array}{c}0 \\
(0.0 \%)\end{array}$ & $\begin{array}{c}2 \\
(1.6 \%)\end{array}$ & $\begin{array}{c}14 \\
(11.2 \%)\end{array}$ & $\begin{array}{c}86 \\
(68.8 \%)\end{array}$ & $\begin{array}{c}23 \\
(18.4 \%)\end{array}$ & 4.040 & 0.601 \\
\hline $\begin{array}{l}\text { I am ready to apply } \\
\text { M-learning in the future }\end{array}$ & $\begin{array}{c}0 \\
(0.0 \%)\end{array}$ & $\begin{array}{c}3 \\
(2.4 \%)\end{array}$ & $\begin{array}{c}10 \\
(8 \%)\end{array}$ & $\begin{array}{c}87 \\
(69.6 \%)\end{array}$ & $\begin{array}{c}25 \\
(20 \%)\end{array}$ & 4.072 & 0.6114 \\
\hline
\end{tabular}

seen in Table 2, the mean value for each of the statements is either almost 4 or more than 4 . This indicates that primary school science teachers in the state of Johor are ready to use M-Learning during their teaching and learning sessions. Therefore, the role of the teachers is one of the motivating factors encouraging the application of M-Learning in education.

\section{Discussion}

\subsection{Acceptance of M-Learning}

In order to determine whether M-Learning has a positive effect on students, the level of acceptance of M-Learning should be analyzed. It is evident, however, that the use of ICT in learning and facilitating, as well as in the management and administration process in Malaysia, enables the obtaining of information at any time or place (Scott et al., 2017; Syazwani, Siti Fadzilah \& Hazura 2018).

Based on all the primary constructs, the findings of this study on the acceptance and readiness to use M-Learning in teaching show that science teachers 
strongly accept the use of M-Learning and they have formed a positive attitude towards the use of ICT in learning and facilitating. This positive result can also create a productive M-Learning environment because it is not restricted by factors of time, distance, and geography. The findings also support the opinions of Al-Hunaiyyan, Alhajri and Al-Sharhan (2016) who believe that this technology hasthe potential to further improve the learning and facilitating process and the level of interaction between students and teachers.

M-Learning also makes the learning and facilitating process more enjoyable and exciting because it is implemented in an environment designed by wireless technology. Apart from being environmentally friendly, its method is flexible and easily adaptable according to location and situation. In applying Mobile-Learning, teachers should use appropriate learning strategies which are suitable to match the students' level of thinking. Teachers should also generate strategies to unleash the creativity of students to be applied in the 21st century learning environment. In Malaysia, the use of mobile technology in particular is seen as a widespread culture and is considered to be a potential medium in the teaching process.

Krish, Hussin, Manap, and Amir (2012) through their survey discovered that the use of smartphones among Malaysians is among the highest in the world, with its usage found to be higher than computer usage. This indicates that M-Learning can very likely be implemented successfully in Malaysia, especially for science subjects.

\subsection{Readiness to Use M-Learning}

The level of readiness of teachers from the aspect of knowledge is high. Although some teachers do not apply M-Learning in their learning and facilitating, they acknowledge the usefulness of mobile technology to help in learning and facilitating sessions.

Teachers' attitude is another aspect of readiness that should be taken into consideration when using mobile technology in learning and facilitating science. Different opinions on the use of mobile devices indirectly affect the process of change. However, from the results of the analysis, it appears that these teachers have a positive attitude regarding the use of mobile technology in education. This is shown from the total mean values and standard deviations which are mostly focused on medium to high levels.

It follows that science teachers need to be prepared to increase their level of knowledge regarding the use of mobile technology. This is considering that technology evolves and changes at a fast past and teachers who are not willing to keep up with the latest developments in technology will be left behind. This should not happen because teachers are the frontrunners who carry the task of conveying information to students through learning and facilitating in school. Therefore, teachers should take the initiative to learn and explore mobile technology. Teachers' attitude must also be positive and mobile technology must be accepted as an essential factor to help the learning and facilitating process as well 
as to improve student excellence. According to Mahat, Fauzi, Ayub, and Luan (2012), before teachers can apply mobile technology in the classroom, they themselves should take steps to improve their existing skills and knowledge so that the teaching and learning process can run smoothly.

\section{Conclusion}

Through these findings, it can be concluded that M-Learning is an appropriate method of learning to be implemented in schools. Since almost all of the schools in Malaysia are equipped with internet facilities to facilitate the M-Learning strategy, no major restriction should occur for this implementation. For researchers who wish to conduct studies on M-Learning in the future, it is proposed that research be conducted to learn more about other appropriate learning strategies for M-Learning or the effect of using mobile devices to teach other subjects apart from Science. The researchers for this study hope that M-Learning will be used in schools and that any digital gap issues can be overcome effectively.

\section{Implications}

The traditional learning method is said to be less successful in creating an active and conducive learning environment compared to the M-Learning method. Students of today who are called "Net Generation" or "Millennial" students are different than earlier generations, thus new ways to teach them are needed.

Millennial students are wise but impatient. They expect immediate results and are always attracted to sophisticated electronic tools. Therefore, based on their natural attitudes, the M-Learning method is more suited to the new generation. It is also said that the development of the Industrial Revolution 4.0 which emphasizes the use of the Internet of Things (IoT) and digital devices will broadly enhance the quality of learning in the education and employment sectors. In conclusion, M-Learning is a new dimension of learning that benefits the current generation of users.

In addition, M-Learning is also suited to the current environment that prioritizes the effective use of time, fast-paced information search, and smart financial planning. With the global power to obtain information at the fingertip, mobile learning is expected to produce knowledgeable people as well as improve the standard of living of the nation. Governments and NGOs should take the opportunity to embrace M-Learning due to the privileges and advantages it offers. Hence, all parties are advised to work together to overcome any problems in applying M-Learning in Malaysia's education system.

\section{Future Recommendations}

This study can be further expanded by applying it into another study which seeks to explore the distinction of M-Learning between primary school science teachers and secondary school science teachers. From the findings, researchers 
can also explore the acceptance and benefit factor on the use of M-Learning among primary school science teachers. Researchers can also apply qualitative research methods such as interviews and observations in future studies. Studies should also be conducted in urban, rural, vernacular, and secondary schools in Malaysia. Based on these findings, comparative studies can also be conducted on the acceptance factor for each of these school categories.

\section{Acknowledgements}

This research was partially supported by grant received from the Faculty of Education, Universiti Kebangsaan Malaysia code PP-FPEND-2019.

\section{Conflicts of Interest}

The authors declare no conflicts of interest regarding the publication of this paper.

\section{References}

Ahmed, S., \& Parsons, D. (2013). Abductive Science Inquiry Using Mobile Devices in the Classroom. Computers and Education, 63, 62-72. https://doi.org/10.1016/j.compedu.2012.11.017

Al-Hunaiyyan, A., Alhajri, R. A., \& Al-Sharhan, S. (2016). Perceptions and Challenges of Mobile Learning in Kuwait. Journal of King Saud University-Computer and Information Sciences, 30, 279-289.

Azizah, J., \& Siew, L. C. (2018). Design and Development of Malaysia Sexuality Education Multimedia Courseware. Journal of Education Malaysia, 34, 125-142.

Camilleri, M. A., Alexander, C. F., Gary, M. M., \& Phil, G. D. (2017). The Technology Acceptance of Mobile Applications in Education (pp. 1-9).

Cheong, C., Bruno, V., \& Cheong, F. (2012). Designing a Mobile-APP-Based Collaborative Learning System. Journal of Information Technology Education Innovations in Practice, 11, 97-119. https://doi.org/10.28945/1582

Ismail, I., Bokhare, S. F., Azizan, S. N., \& Azman, N. (2013). Teaching via Mobile Phone : A Case Study on Malaysian Teachers' Technology Acceptance and Readiness. Journal of Educators Online, 10, 1-38. https://doi.org/10.9743/JEO.2013.1.3

Jou, M., Lin, Y. T., \& Tsai, H. C. (2016). Mobile APP for Motivation to Learning: An Engineering Case. Journal of Interactive Learning Environments, 24, 2048-2057. https://doi.org/10.1080/10494820.2015.1075136

Karch, K. (2014) An Investigation of Perceptions about Smart Mobile Phone Usage as an Instructional Tool in a High School Classroom. Journal of Computer Information Systems, $15,56-70$.

Krish, P., Hussin, S., Manap, M. R., \& Amir, Z. (2012). Mobile Learning Readiness among Malaysian Students at Higher Learning Institutes. Asian Social Science, 8, 276-283. https://doi.org/10.5539/ass.v8n12p276

Lu, J., Liu, C., \& Wei, J. (2017). How Important Are Enjoyment and Mobility for Mobile Applications? Journal of Computer Information Systems, 571, 1-12. https://doi.org/10.1080/08874417.2016.1181463

Mahat, J., Fauzi, A., Ayub, M., \& Luan, S. (2012). An Assessment of Students' Mobile Self-Efficacy, Readiness and Personal Innovativeness towards Mobile Learning in 
Higher Education in Malaysia. Procedia-Social and Behavioral Sciences, 64, 284-290. https://doi.org/10.1016/j.sbspro.2012.11.033

Norazah, M. N., \& Helmi, N. (2018). Cross-Culture Learning Via Massive Open Online Courses for Higher Education. Journal of Education Malaysia, 43, 35-39.

Norlidah, A. (2013). Design and Development Research: Emergent Trends in Educational Research (pp. 1-16).

Oz, H. (2014). Prospective English Teachers' Ownership and Usage of Mobile Devices AsM-Learning Tools. Procedia-Social and Behavioral Sciences, 141, 1031-1041. https://doi.org/10.1016/j.sbspro.2014.05.173

Rian, V., \& Kamisah, O. (2018). The Effectiveness of Various Instructional Medium in Improving Students' Science Process Skills. Journal of Education Malaysia, 41-42, 111.

Rikala, J., Hiltunen, L., \& Vesisenaho, M. (2014). Teachers' Attitudes, Competencies, and Readiness to Adopt Mobile Learning Approaches (pp. 1-8). 2014 IEEE Frontiers in Education Conference (FIE) Proceedings.

https://doi.org/10.1109/FIE.2014.7044408

Ronizam, I., Shahrul Niza Samsudin, A. W. S., Norzaimah, Z., \&, \& Dina, S. Z. (2016). Literature Review on the Islamic Mobile Applications. Journal of Global Business and Social Entrepreneurship (GBSE), 2, 174-182.

Scott, R. B., Ed, R., Raymond, V., Wade, G., Victor, L., \& Louis, N. (2017). Relationship between Access to Mobile Devices, Student Self-Directed Learning and Achievement, Journal of Technology Education, 29, 2-24.

Shi, Z., Luo, G., \& He, L. (2017). Mobile-Assisted Language Learning Using Wechat Instant Messaging. International Journal of Emerging Technologies in Learning, 12, 16-26. https://doi.org/10.3991/ijet.v12i02.6681

Syazwani, A., Siti Fadzilah, M. N., \& Hazura, M. (2018). The Usage of TVET Mobile Application. Journal of Education Malaysia, 4, 34-46.

Taylor, J., \& Sharples, M. (2006). Towards a Task Model for Mobile Learning : A Dialectical Approach Claire O'Malley Giasemi Vavoula. International Journal of Learning Technology, 2, 138-158. https://doi.org/10.1504/IJLT.2006.010616 